\title{
Diagnosis-Related Groups for Stroke in Europe: Patient Classification and Hospital Reimbursement in 11 Countries
}

\author{
Mikko Peltola ${ }^{a}$ Wilm Quentin ${ }^{b}$ on behalf of the EuroDRG Group \\ ${ }^{a}$ Centre for Health and Social Economics, National Institute for Health and Welfare, Helsinki, Finland; \\ ${ }^{b}$ Department of Health Care Management, Technische Universität Berlin, Berlin, Germany
}

\section{Key Words}

Acute stroke · Diagnosis-related groups · Europe ·

Hospital financing $\cdot$ Cerebral infarct

\begin{abstract}
Background: Diagnosis-related groups (DRGs) are increasingly being used for various purposes in many countries. However, there are no studies comparing different DRG systems in the care of stroke. As part of the EuroDRG project, researchers from 11 countries (i.e. Austria, England, Estonia, Finland, France, Germany, Ireland, the Netherlands, Poland, Sweden and Spain) compared how their DRG systems deal with stroke patients. The study aims to assist clinicians and national authorities to optimize their DRG systems. Methods: National or regional databases were used to identify hospital cases with a diagnosis of stroke. DRG classification algorithms and indicators of resource consumption were compared for those DRGs that individually represent at least $1 \%$ of stroke cases. In addition, standardized case vignettes were defined, and quasi prices according to national DRGbased hospital payment systems were ascertained. Results: European DRG systems vary widely: they classify stroke patients according to different sets of variables (between 1 and 7 classification variables) into diverging numbers of DRGs
\end{abstract}

(between 1 and 10 DRGs). In 6 of the countries more than half of the patients are concentrated within a single DRG. The countries' systems also vary with respect to the evaluation of different kinds of stroke patients. The most complex DRG is considered 3.8 times more resource intensive than an index case in Finland. By contrast, in England, the DRG system does not account for complex cases. Comparisons of quasi prices for the case vignettes show that hypothetical payments for the index case amount to only EUR 907 in Poland but to EUR 7,881 in Ireland. Conclusions: Large variations in the classification of stroke patients raise concerns whether all systems rely on the most appropriate classification variables and whether the DRGs adequately reflect differences in the complexity of treating different groups of patients. Learning from other DRG systems may help in improving the national systems. Clinicians and national DRG authorities should consider how other countries' DRG systems classify stroke patients in order to optimize their DRG system and to ensure fair and appropriate reimbursement. In future, quantitative research is needed to verify whether the most important determinants of cost are considered in different patient classification systems, and whether differences between systems reflect country-specific differences in treatment patterns and, most importantly, what influence they have on patient outcomes.

Copyright $\odot 2013$ S. Karger AG, Basel

\section{KARGER}

Fax +41613061234

E-Mail karger@karger.ch

www.karger.com (c) 2013 S. Karger AG, Basel

$1015-9770 / 13 / 0352-0113 \$ 38.00 / 0$

Accessible online at:

www.karger.com/ced
Mikko Peltola

Centre for Health and Social Economics

National Institute for Health and Welfare, Mannerheimintie 166

FI-00270 Helsinki (Finland)

E-Mail mikko.peltola@thl.fi 


\section{Introduction}

Diagnosis-related groups (DRGs) are used in Europe for a range of different purposes: they form the basis of hospital performance comparisons, they are used to facilitate hospital management, and in current DRGbased hospital payment systems, DRGs define the payment categories, i.e. hospital products [1,2]. DRGs are 'diagnosis-related' groups of patients that have (a) similar resource consumption patterns and that are (b) clinically meaningful [3]. They are defined by patient classification systems - i.e. DRG systems - which group treatment cases into DRGs on the basis of classification variables such as diagnoses, procedures and demographic characteristics.

It is very important that DRGs are sufficiently homogenous in terms of treatment costs. Otherwise, DRG-based performance comparisons do not adequately control for differences of patients within groups; and reimbursement for a large number of patients is not appropriate. In order to assure homogenous groups of patients, DRG systems need to consider the most important determinants of resource consumption as classification variables. In many countries, professional medical associations, specialist experts or consultants formally participate in the process of selection, definition and update of classification criteria via committees, expert hearings or consultations [46]. It is, therefore, of the utmost importance for specialist groups such as neurologists that they are aware of how their respective patients are classified into DRGs in order to assess whether current classification variables adequately reflect differences in the complexity of treating different groups of patients. Learning from other DRG systems may help in improving the national systems.

This study performs a comprehensive assessment of DRG systems across 11 European countries and has 3 main objectives: (1) to assess classification variables and algorithms used to group patients with stroke into DRGs; (2) to compare variations in DRG weights, and (3) to determine DRGs and hospital price levels for 6 case vignettes of stroke patients with different combinations of diagnostic and treatment variables.

\section{Materials and Methods}

Definition of Episode of Care and Stroke Index Case

Similar methods have been reported previously for another episode of care [7]. As part of the EuroDRG project, researchers from 11 countries (i.e. Austria, England, Estonia, Finland, France, Germany, Ireland, the Netherlands, Poland, Sweden and Spain) agreed
Table 1. Definition of the episode of care and the index case

\begin{tabular}{ll}
\hline $\begin{array}{l}\text { Definition } \\
\text { Name }\end{array}$ & Stroke \\
Defined by & Primary diagnosis \\
Primary diagnosis & I61 - intracerebral haemorrhage \\
& I63 - cerebral infarction \\
& I64 - stroke, not specified as haemor- \\
& rhage or infarction
\end{tabular}

Index case

Female, age 78 years, cerebral infarction without complicating secondary diagnoses, no major procedures, treated as inpatient, no death during the hospital stay

upon a common definition for a stroke episode of care. The definition requires a diagnosis of stroke in the International Classification of Diseases, 10th edition (ICD-10), and is presented in table 1. A stroke index case was defined to facilitate comparisons of relative resource intensity of DRGs within countries (table 1). The index case is characterized by the most common patient and treatment characteristics of uncomplicated stroke cases in hospitals of the selected countries: a 78-year-old patient without complications, no major procedures, discharged alive, and treated as inpatient.

\section{Data Sources}

In each country, researchers identified national or regional hospital databases and obtained access to all information necessary for the purposes of this study. The number of stroke cases conforming to our definition and the corresponding DRGs were extracted from the databases. Table 2 provides an overview of the databases and data years available. No ethical permissions were required for this analysis.

\section{Analysis of Patient Classification Systems}

Detailed comparative analyses of classification variables and grouping algorithms of national DRG systems [8-16] were performed for the most frequent DRGs, i.e. those DRGs that individually represented at least $1 \%$ of stroke cases in the relevant database. Grouping algorithms were mapped graphically to facilitate comparisons between systems (fig. 1a, b). In addition, the percentage of all stroke cases grouped into each DRG was calculated. In order to compare DRG weights (i.e. relative weights, scores, tariffs) within and across countries, a DRG weight index was calculated with the index case (table 1) assuming a value of 1. The index score of all other DRGs was calculated by dividing the national measure of DRG weight of each DRG by that of the index DRG.

\section{DRGs and Hospital Quasi Prices}

In addition to the index case, 6 stroke cases with different combinations of primary and secondary diagnoses, procedures, length of stay, and stroke unit care were defined (table 3 ). Case vignettes were selected specifically to illustrate differences in DRG systems across countries, i.e. only patient and treatment characteristics were specified that are relevant for the classification of patients and reimbursement of hospitals in at least one country but not in all 
Table 2. Data years and databases by country

\begin{tabular}{|c|c|c|c|}
\hline Country & $\begin{array}{l}\text { Data } \\
\text { year }\end{array}$ & $\begin{array}{l}\text { Number } \\
\text { of cases }\end{array}$ & Source of data \\
\hline Austria & 2008 & 18,092 & $\begin{array}{l}\text { Leistungsorientierte Krankenanstaltenfinanzierung database of the Bundesministerium für } \\
\text { Gesundheit }\end{array}$ \\
\hline England & $2007 / 2008$ & 70,256 & Hospital Episode Statistics \\
\hline Estonia & 2008 & 5,729 & Estonia Health Insurance Fund database \\
\hline Finland & 2008 & 13,095 & Hospital Discharge Register \\
\hline Germany & 2008 & 267,592 & $\begin{array}{l}\text { Fallpauschalenbezogene Krankenhausstatistik (DRG statistic) of the Federal Statistical Office } \\
\text { (Destatis) }\end{array}$ \\
\hline Ireland & 2008 & 5,380 & Hospital Inpatient Enquiry Scheme database of the Health Services Executive \\
\hline The Netherlands & 2008 & 31,663 & Diagnose Behandeling Combinaties Onderhoud database \\
\hline Poland & 2009 & 87,397 & Register of episodes of care and reimbursements of the National Health Fund \\
\hline Spain (Catalonia) & 2008 & 11,089 & Hospital Minimum Basic Data Set database of the Public Hospital Network of Catalonia \\
\hline
\end{tabular}

${ }^{1}$ Data from 2008 were regrouped by the national DRG authority into the 2010 version of GHM (GHM version 11 b).

other countries. Case vignettes 1-4 are patients suffering from cerebral infarction. Case vignettes 5 and 6 are patients with intracerebral haemorrhage.

DRG-based hospital payment systems differ between and often even within countries, thus complicating comparisons. Therefore, quasi prices were ascertained for each case vignette and for the index case using an approach similar to that of Koechlin et al. [17]. Quasi prices were calculated by converting national measures of DRG weight (i.e. cost weights, average tariffs, scores - taking account of outlier deduction/add-ons or additional payments where possible) into monetary values using national conversion rates. If necessary, prices were deflated to year 2008 national currency using national gross domestic product deflators [18], and converted to euros using average currency exchange rates for the year 2008 [19]. In addition, a quasi price index was calculated with the index case assuming a value of 1 . The index score of all other case vignettes was calculated by dividing the value of the quasi price of each case vignette by that of the index case.

\section{Results}

Figure 1a and $\mathrm{b}$ provides a graphic illustration of grouping algorithms and classification variables of DRG systems in 11 European countries. The figures include classification variables of those DRGs that individually represent at least $1 \%$ of stroke cases in each country. DRGs containing less than $1 \%$ of cases in the national database but essential for understanding the grouping logic are shaded in light grey and are not considered in the following analysis. The index DRGs are highlighted in dark grey. On the left-hand side, the figures specify for each country the version of the DRG system and the percentage of all identified stroke cases that are shown in the graph. The two last columns on the right show the percentage of stroke cases covered by each DRG and the DRG weight index.

\section{Overview: Number of DRGs, Number of Classification Variables}

The figures demonstrate that there is great variation in DRG systems across Europe. The percentage of all stroke cases covered by the DRGs included in our analysis ranges from $90 \%$ in Germany to $100 \%$ in the Netherlands. In Estonia, almost all stroke cases are classified into a single DRG, while in France and Germany 10 different DRGs with more than $1 \%$ of stroke cases exist.

In addition, the number of classification variables varies: the English system differentiates only between main diagnoses when classifying stroke patients. By contrast, the German system differentiates (1) main diagnoses, (2) procedures (including systemic thrombolysis, rehabilitation and artificial ventilation), (3) death during admission, (4) complications (i.e. motor dysfunction), (5) stroke unit treatment, and (6) length of stay.

\section{Characteristics of Classification Variables}

In all countries' systems, a primary diagnosis of stroke is considered at an early stage in the grouping algorithm. However, only 6 DRG systems differentiate between patients with a primary diagnosis of cerebral infarction and those with a primary diagnosis of intracranial or intracerebral haemorrhage.

Similarly, the presence of relevant secondary diagnoses, i.e. complications and comorbidities, influences the 


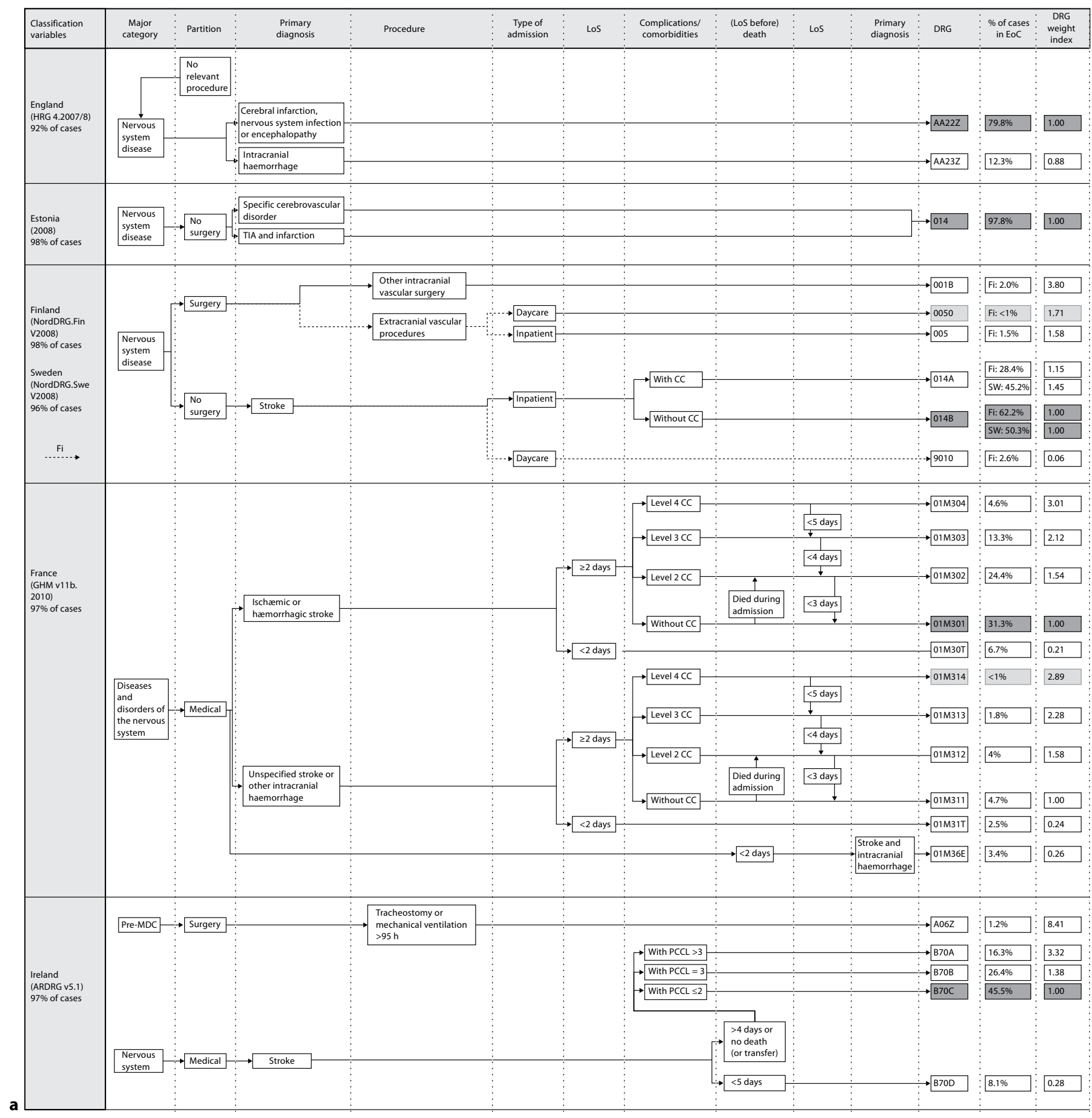

Fig. 1. Graphic illustrations of algorithms and variables. LoS = Length of stay; $\mathrm{EoC}=$ episode of care; $\mathrm{HRG}=$ healthcare resource group; TIA = transient ischaemic attack; $\mathrm{Fi}=$ Finland; $\mathrm{CC}=\mathrm{com}$ plications and comorbidities; $\mathrm{Sw}=$ Sweden; $\mathrm{ICB}=$ intracranial bleeding; $\mathrm{ST}=$ systemic thrombolysis; $\mathrm{PCCL}=$ patient clinical complexity level; $\mathrm{MDC}=$ main diagnostic category. $\mathbf{a}$ Grouping algorithms and classification variables of DRG systems in 6 European countries. b Grouping algorithms and classification variables of DRG systems in 5 European countries. 


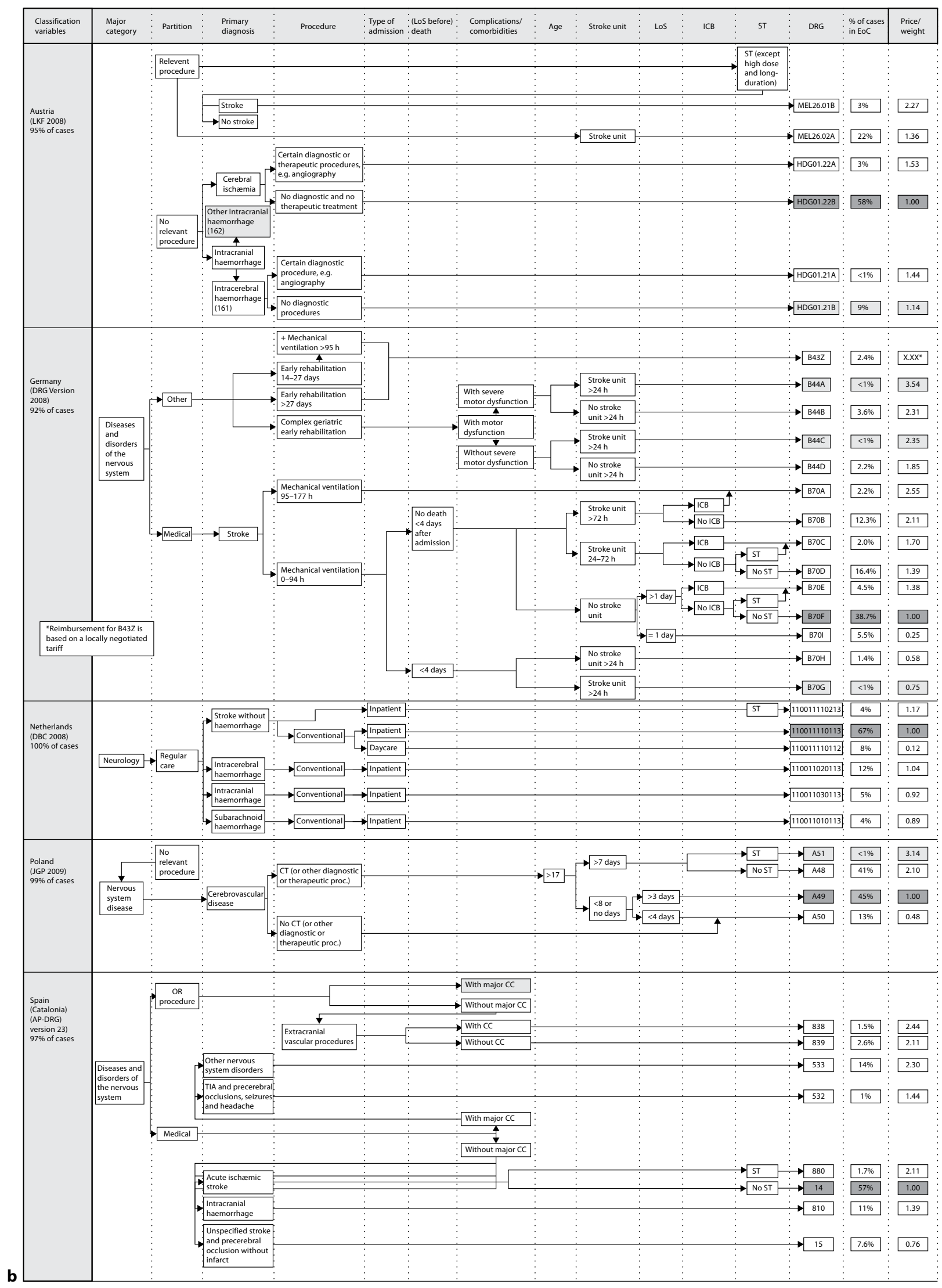


Table 3. Case vignettes: patient classification variables

\begin{tabular}{|c|c|c|c|c|c|c|c|c|c|}
\hline Case & $\begin{array}{l}\text { Primary } \\
\text { diagnosis }\end{array}$ & $\begin{array}{l}\text { Secondary } \\
\text { diagnoses }\end{array}$ & Specific procedures & Sex & $\begin{array}{l}\text { Age } \\
\text { years }\end{array}$ & Setting & $\begin{array}{l}\text { Death during } \\
\text { admission }\end{array}$ & $\begin{array}{l}\text { Length } \\
\text { of stay } \\
\text { days }\end{array}$ & $\begin{array}{l}\text { Stroke } \\
\text { unit }\end{array}$ \\
\hline 1 & I63.0 & & & female & 78 & day care & no & 0 & no \\
\hline 2 & I63.0 & & 99.10 & female & 78 & inpatient & yes & 4 & no \\
\hline 3 & I63.0 & & 99.10 & female & 78 & inpatient & no & 7 & no \\
\hline 6 & $\mathrm{I} 61.0$ & $\mathrm{E} 11.8, \mathrm{I} 48$ & $93.12,93.72,93.74$ & female & 78 & inpatient & no & 10 & yes \\
\hline
\end{tabular}

Primary and secondary diagnoses assessed by ICD-10, specific procedures by ICD9-CM. 'Stroke unit' concerns only Germany and Austria, as based on the DRG algorithms the other countries' classification systems do not take into account the treatment unit. E11.8 = Non-insulin-dependent diabetes mellitus with unspecified complications; I48 = atrial fibrillation and flutter; $93.12=$ physical therapy exercises: other active musculoskeletal exercise; 93.72 = speech and reading rehabilitation and rehabilitation of the blind: dysphasia training; $93.74=$ speech and reading rehabilitation and rehabilitation of the blind: speech defect training; $99.10=$ injection or infusion of thrombolytic agent.

classification of patients in the majority of countries. In all countries included in figure 1b, i.e. Austria, Germany, the Netherlands, Poland and Spain, patients treated with thrombolysis are assigned into specific groups. Other treatment-related classification variables include extracranial or intracranial vascular procedures (Finland and Spain), mechanical ventilation (Ireland and Germany), length of stay (France, Germany, Ireland and Poland) and in-hospital rehabilitation (Germany).

Provider and setting characteristics are considered by 5 DRG systems (i.e. in Austria, Finland, Germany, the Netherlands and Poland). In Finland and the Netherlands, day case admissions are identified by the grouping algorithm and are assigned into specific groups. Treatment in a stroke unit is used as a classification variable only in Austria, Germany and Poland.

\section{Distribution of Stroke Cases and Variation of DRG Weights}

In all countries except for Sweden, the vast majority of stroke cases are grouped into the shadowed DRG containing the index case (fig. $1 \mathrm{a}, \mathrm{b}$ ), i.e. between $31 \%$ in France and 98\% in Estonia. In fact, in Austria, England, Estonia, Finland, the Netherlands and Spain, more than half of the patients are concentrated within a single DRG.

In those countries, where comorbidities are taken into account in the grouping algorithms, DRGs for patients with complications have DRG weights that are much higher than the index DRG. Similarly, in countries where stroke unit treatment or systemic thrombolysis are used as classification variables, DRG weights for patients treat- ed in stroke units or with thrombolysis have much higher DRG weights. In fact, stroke unit treatment for more than $72 \mathrm{~h}$ doubles the DRG weight in Germany (G-DRG B70B), and increases the DRG weight by $36 \%$ in Austria (MEL26.02A). Systemic thrombolysis increases the DRG weight (compared with the index DRG) by $17 \%$ in the Netherlands, and more than doubles the DRG weight in Austria and Spain.

\section{DRGs and Hospital Quasi Prices for Case Vignettes}

Table 4 shows the comparison of DRGs and hospital quasi prices for the index case and the 6 case vignettes under the assumption that hospital payment would be exclusively based on DRGs. For each case vignette, the first column specifies the DRG into which a case vignette patient would be classified, and the second column specifies for each patient the corresponding quasi price.

Partially reflecting differences in terms of gross domestic product per capita [18], the quasi price of the index case varies substantially across countries, ranging from EUR 907 in Poland to EUR 7,881 in Ireland. However, countries paying a higher price for one type of patient do not necessarily pay a higher price for all kinds of patients. For example, hospitals in England would receive much higher payments than hospitals in Germany for a patient with ischaemic stroke, treated with thrombolysis and discharged alive after 7 days (patient 3). Conversely, hospitals in Germany would receive higher payments than hospitals in England for a patient with haemorrhagic stroke, treated in a stroke unit and discharged alive after 10 days (patient 6). Figure 2 facilitates these kinds of comparisons 


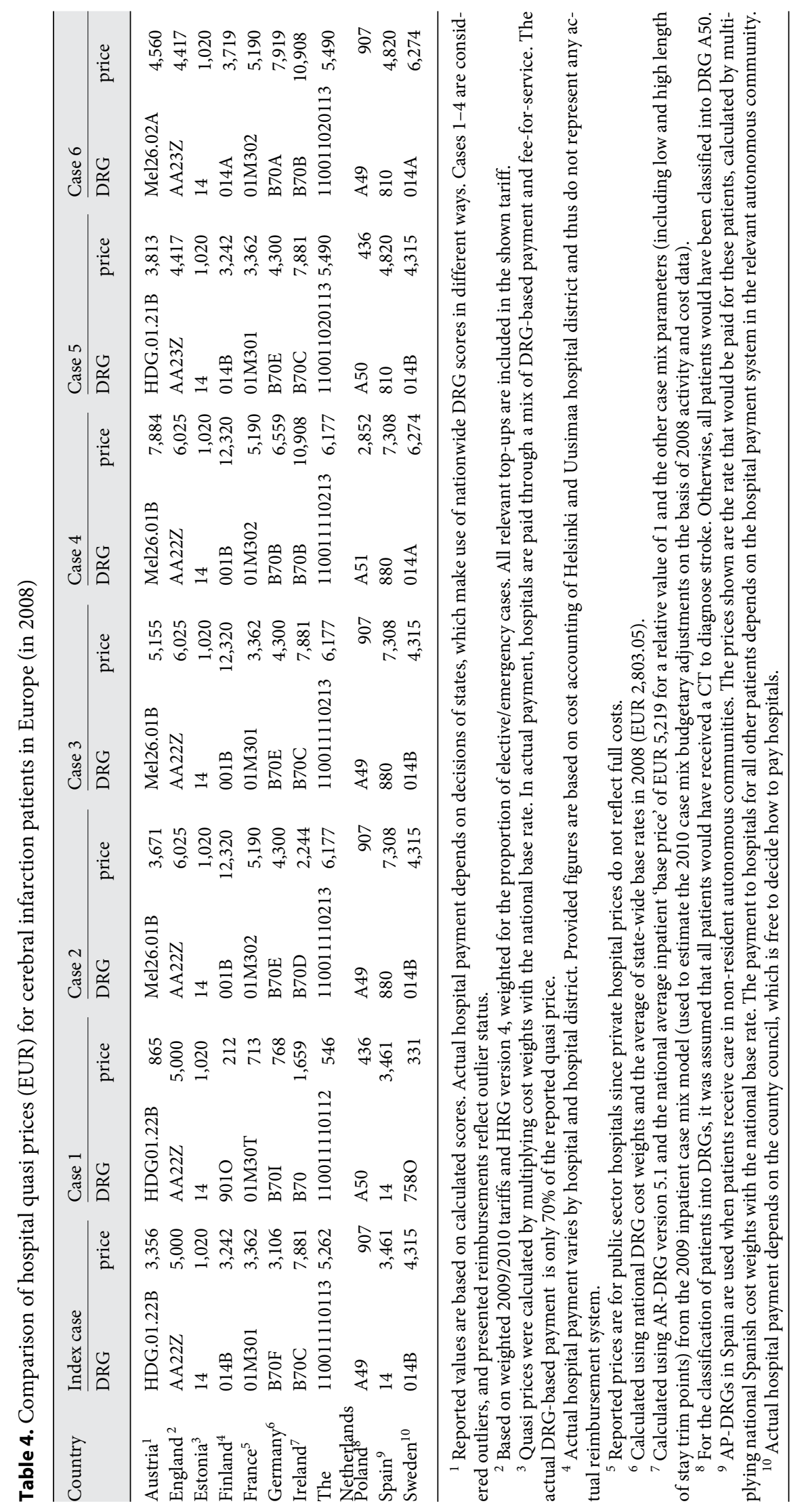




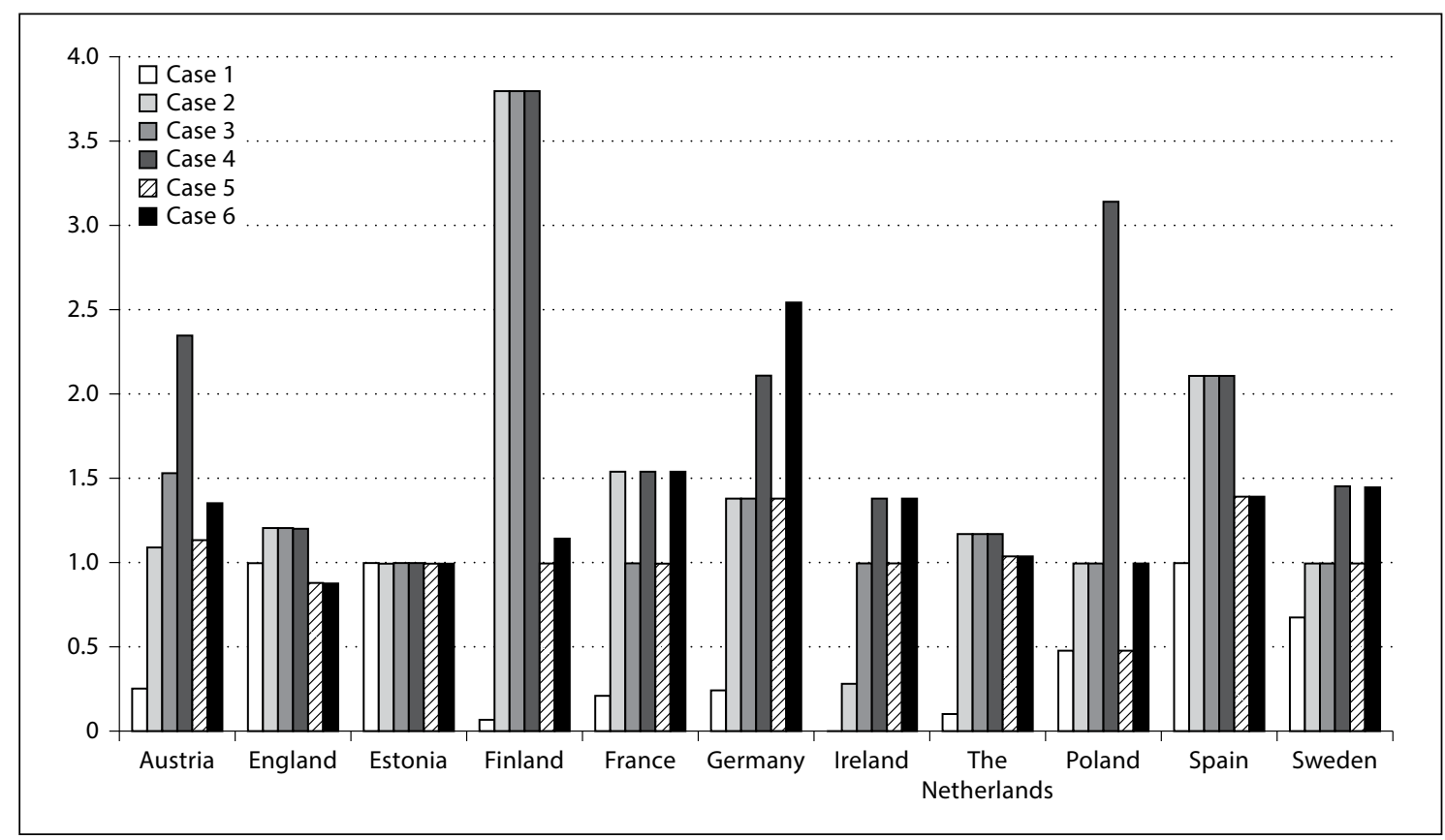

Fig. 2. Comparison of price indices for the stroke case vignettes in 11 European countries (the price index of the index case equals 1.0 in each country).

by presenting the results of table 4 using the quasi price index score, which compares hospital quasi prices within countries for each patient to the quasi price for the index case. Figure 2 illustrates that in England, Estonia and the Netherlands the variation of quasi prices is very small. Moreover, figure 2 shows that countries award the highest payments for different kinds of patients.

\section{Discussion}

This is the most comprehensive available comparative analysis of grouping algorithms, classification variables and prices for stroke patients in different DRG-based hospital payment systems in Europe. It shows great variation across countries: (1) in the number of DRGs; (2) in the characteristics of classification variables; (3) in the degree of differentiation between complex and less complex cases, and (4) in the quasi prices for different types of patients (case vignettes).

As DRGs are used to assess the performance of hospitals (including that of neurologists) and to determine hospital payment $[1,2,20]$, it is important that DRG systems consider the most appropriate classification variables to assure that performance comparisons and hospital payments are fair $[21,22]$. Given the identified large varia- tions between DRG systems in different countries for the classification of stroke patients, it is at least questionable whether all DRG systems consider as classification variables the most important determinants of resource consumption.

Neurologists can influence decisions about classification variables in their roles as advisors to national authorities responsible for defining and updating the patient classification systems of their countries [4-6]. In Germany, neurologists have played an important role in the process of optimizing the classification of stroke patients [23]. International comparisons can provide a useful new perspective when thinking about how to improve an existing DRG system. However, before drawing conclusions on the basis of this study's findings, limitations of our data and methodology need to be considered.

Firstly, our study used routine inpatient databases to identify patients and to assess the relative importance of different DRGs in different countries. As highlighted by the Hospital Data Project, there are differences in coding practices across countries, and the quality of data is not always comparable [24]. Secondly, differences in hospital payment systems between countries complicate comparative analyses of payment levels (table 4). On the one hand, different countries set DRG-based payment rates at different levels as they include different cost cat- 
egories. For example, in Germany, fixed capital costs are not included in DRG-based payment rates, while most other countries included this cost category in payment rates [17]. On the other hand, different systems of additional payments exist, e.g. England assigns additional ('unbundled') healthcare resource groups for certain diagnostic evaluations such as CT scans and for intensive care unit treatment ('critical care') [25], and Poland and Austria have additional per diem based payments for stays in intensive care units. Furthermore, the Netherlands and Finland can have several DRGs per hospital stay, each leading to additional DRG-based payments, and several countries adjust payments in order to account for differences between hospitals or regions. Therefore, the absolute price levels should not be directly interpreted as reflecting more expensive care in one country compared to another. However, relative price levels within countries that were used for comparisons in figures $1 \mathrm{a}, \mathrm{b}$, and 2 should be less affected by differences in payment systems or cost-accounting methods as they were always compared to the in-country DRG index case. Also, the interpretation of the relative prices is simple: an index score of 1.50 (in fig. $1 \mathrm{a}, \mathrm{b}$ or 2) indicates $50 \%$ higher compensation than is given for the index case. Thirdly, as we limit our analysis to those more frequent DRGs that account for at least $1 \%$ of cases in our databases, and to patients with more common combinations of diagnoses and procedures, we partially neglect how different systems deal with rare outliers, which may, however, be particularly relevant for reimbursement. Finally, our data did not allow us to identify reasons for the differences in DRG systems and hospital payments between countries. Yet, future research could illuminate whether some countries intentionally did not include certain classification variables in their DRG systems.

In spite of these limitations, our study has major implications for neurologists and national authorities involved in the redesigning of DRG systems. First, awareness about classification algorithms and variables in other countries should encourage neurologists to think about alternative and possibly better ways to classify their patients into DRGs. For example, the treatment of stroke patients in dedicated stroke units has been recommended by European and American guidelines for the management of stroke patients $[26,27]$. However, treatment in a stroke unit is more expensive than treatment on a general medical ward $[28,29]$. At the time of our study, these extra costs were not adequately reimbursed in the majority of countries, as the treatment of patients within the setting of a stroke unit was taken into account only by the DRG systems in Austria, Germany and Poland. Since then, stroke unit care has been incorporated into the 'best practice tariff in England [30] but - to our knowledge other countries have not explicitly incorporated stroke unit care into their DRG-based hospital payment systems. Similarly, while most countries' DRG-based hospital payment systems assign higher payments if treatment includes thrombolysis, this costly but highly effective [31] and recommended $[26,27]$ intervention is not taken into account by DRG systems in Estonia, Finland, France, Ireland and Sweden. Furthermore, this has not changed since the time of our study. Therefore, Estonia, Finland, France, Ireland, the Netherlands, Spain and Sweden could investigate whether their DRG algorithms would be improved by introducing classification variables for stroke unit treatment or systemic thrombolysis.

Second, numerous studies have identified stroke severity to be the most important determinant of resource use in the treatment of stroke patients [32-37]. However, stroke severity is not included as a classification variable in any of the DRG systems analysed. While possibilities exist for stratifying stroke patients according to severity using neuroimaging studies [32] or the National Institute of Health Stroke Scale, ICD-10 codes for different severity levels of stroke do currently not exist, which would be a prerequisite for incorporating severity into DRG systems. By contrast, secondary diagnoses, which have also been found to be predictors of resource use [32, 33, 36] are considered in 5 of the analysed DRG systems. However, Austria, England, Estonia, the Netherlands and Poland should assess whether the homogeneity of DRGs could be improved by incorporating secondary diagnoses into their classification algorithms. Possibly, in countries where DRGs do not take into account differences in the complexity of treating different groups of patients, some of the differences in patient populations between hospitals are accounted for through the above-mentioned adjustments outside of the DRG systems. However, ideally, differences in patient characteristics would be accounted for in the patient classification systems and not in the payment systems.

Third, the comparison of DRG weights and quasi prices showed that hospitals in England receive higher payments for patients with ischaemic stroke than for patients with haemorrhagic stroke, while the opposite is true in Austria, Germany and Spain. Interestingly, available studies suggest that, in fact, treatment of haemorrhagic stroke when compared to ischaemic stroke is associated with higher cost in Germany [38] but with lower costs in 
England [39]. It would be interesting to investigate the reasons for these differences and to identify whether the lower costs of treatment for haemorrhagic stroke compared to ischaemic stroke in England are associated with less intensive treatment and whether differences exist in outcomes.

Finally, the aim of any DRG system is to give a concise measure of what hospitals do. This measure is useful only if DRGs describe a sufficiently homogenous group of patients [40]. Therefore, quantitative research is needed to verify whether the most important determinants of cost are considered in different patient classification systems, and whether differences between systems reflect countryspecific differences in treatment patterns and most importantly, what influence they have on patient outcomes. The third phase of the EuroDRG project attempts to contribute to this discussion. However, it is also important for neurologists and other medical specialists to be aware of the significance of adequately designed DRG systems and to engage in optimizing these systems. Information presented in this article about how DRG systems classify stroke patients can help neurologists to engage with national DRG authorities. Ultimately, this contributes to assuring adequate reimbursement for treated patients and fair performance comparisons on the basis of DRGs.

\section{Acknowledgements}

The findings and results presented in this article were generated in the framework of the project 'Diagnosis-Related Groups in Europe: Towards Efficiency and Quality (EuroDRG)'. We would like to thank Ms. Claudia Reiche for assistance in editing figure 1a and $\mathrm{b}$.

The project was funded through the seventh framework programme (FP7) of the European Commission under grant agreement No. 223300.

\section{Disclosure Statement}

The authors have no conflicts of interest.

\section{References}

1 Busse R, Geissler A, Quentin W, Wiley M (eds): Diagnosis-Related Groups in Europe: Moving towards Transparency, Efficiency and Quality in Hospitals. Buckingham, Open University Press and WHO Regional Office for Europe, 2011.

2 Kimberly JR, de Pouvourville G, D’Aunno TA: The Globalization of Managerial Innovation in Health Care. Cambridge, Cambridge University Press, 2008.

$>3$ Fetter RB: Diagnosis related groups: understanding hospital performance. Interfaces 1991;21:6-26.

4 NHS Information Centre for Health and Social Care. The Casemix Service. HRG 4 Design Concepts. Leeds, NHS Information Centre for Health and Social Care, 2007.

5 Institut für das Entgeltsystem im Krankenhaus gGmbH (InEK): Vorschlagsverfahren zur Einbindung des medizinischen, wissenschaftlichen und weiteren Sachverstandes bei der Weiterentwicklung des G-DRG-Systems für das Jahr 2012 (Procedure to allow for the systematic incorporation of medical, scientific, and other expertise for the development of the G-DRG system). Siegburg, Institut für das Entgeldsystem im Krankenhaus gGmbH, 2011.

6 Patris A, Blum D, Girardier M: A change in the French patient classification system. Casemix Q 2001;3:128-138.

$>7$ Quentin W, Scheller-Kreinsen D, Geissler A, Busse R, EuroDRG Group: Appendectomy and diagnosis-related groups (DRGs): patient classification and hospital reimbursement in
11 European countries. Langenbecks Arch Surg 2012;397:317-326.

8 BMGFJ: Krankenanstaltenfinanzierung-LKF - Modell 2008. Vienna, Bundesministerium für Gesundheit, Familie und Jugend, 2008.

9 NHS Information Centre for Health and Social Care: The Casemix Service. HRG4 Reference Cost Grouper - Guide to File Preparation. Leeds, NHS Information Centre for Health and Social Care, 2008.

10 ATIH: Manuel des GHM, version 11. Lyon, Agence de l'Information sur l'Hospitalisation, 2009.

11 Nordic Centre for Classifications in Health Care: NordDRG Users' Manual. Uppsala, Nordic Centre for Classifications in Health Care, 2007.

12 Institut für das Entgeltsystem im Krankenhaus gGmbH (InEK): G-DRG German Diagnosis Related Groups Version 2008: Definitionshandbuch. Siegburg, Institut für das Entgeldsystem im Krankenhaus gGmbH, 2007.

13 Commonwealth Department of Health and Ageing: Australian Refined Diagnosis Related Groups Version 6.0: Definitions Manuals. Canberra, Commonwealth Department of Health and Ageing, 2008.

14 DBC Onderhound. Diagnose Behandeling Combinaties. Utrecht, DBC Onderhound, 2008.

15 The National Health Fund: Jednorodne Grupy Pacjentów - Technical Material. Warsaw, National Health Fund, 2008.

16 3M: All Patients Diagnosis Related Groups
Definitions Manual version 23.0. Wallingford, 3M, 2005.

17 Koechlin F, Lorenzoni L, Schreyer P: Comparing Price Levels of Hospital Services across Countries. Paris, Organisation for Economic Co-operation and Development (OECD), OECD Health Working Papers, 2010.

18 OECD: OECD Health Data 2010: Statistics and Indicators. Paris, Organisation for Economic Co-operation and Development (OECD), 2010.

19 ECB: Statistical Data Warehouse: National Currency per Euro, Annual Bilateral Exchange Rates Time Series. 2011.

20 Cots F, Chiarello P, Salvador X, Quentin W: DRG-based hospital payment: intended and unintended consequences; in Busse $\mathrm{R}$, Geissler A, Quentin W, Wiley M (eds): Diagnosis Related Groups in Europe: Moving towards Transparency, Efficiency and Quality in Hospitals? Buckingham, Open University Press, 2011

21 Schreyögg J, Tiemann O, Busse R: Cost accounting to determine prices: how well do prices reflect costs in the German DRG-system? Health Care Manag Sci 2006;9:269-279.

22 Busse R, Quentin W: Moving towards transparency, efficiency and quality in hospitals: conclusions and recommendations; in Busse $\mathrm{R}$, Geissler A, Quentin W, Wiley M (eds): Diagnosis-Related Groups in Europe: Moving towards Transparency, Efficiency and Quality in Hospitals. Buckingham, Open University Press and WHO Regional Office for Europe, 2011. 
23 Roeder N, Fiori W, Ringelstein EB: Stroke treatment in the 2006 German diagnosis-related group system. Nervenarzt 2006;77:221228.

24 HDP2: Hospital Data Project Phase 2: Final report. The equal need for metadata and data. Prismant, 2008.

25 NHS Information Centre for Health and Social Care. The Casemix Service. Unbundled HRGs by Chapter in HRG4. Leeds, NHS Information Centre for Health and Social Care, 2007.

26 European Stroke Organisation (ESO) Executive Committee, ESO Writing Committee: Guidelines for management of ischaemic stroke and transient ischaemic attack 2008. Cerebrovasc Dis 2008;25:457-507.

-27 Adams HP Jr, del Zoppo G, Alberts MJ, Bhatt DL, Brass L, Furlan A, et al: Guidelines for the early management of adults with ischemic stroke: a guideline from the American Heart Association/American Stroke Association Stroke Council, Clinical Cardiology Council, Cardiovascular Radiology and Intervention Council, and the Atherosclerotic Peripheral Vascular Disease and Quality of Care Outcomes in Research Interdisciplinary Working Groups. The American Academy of Neurology affirms the value of this guideline as an educational tool for neurologists. Circulation 2007;115:e478-534.
28 Saka O, Serra V, Samyshkin Y, McGuire A, Wolfe CC: Cost-effectiveness of stroke unit care followed by early supported discharge. Stroke 2009;40:24-29.

29 Epifanov Y, Dodel R, Haacke C, Schaeg M, Schoffski O, Hennerici M, et al: Costs of acute stroke care on regular neurological wards: a comparison with stroke unit setting. Health Policy 2007;81:339-349.

30 Department of Health: Payment by Results. Guidance for 2011-2012. Leeds, Departmen of Health, 2011.

31 Ehlers L, Andersen G, Clausen LB, Bech M, Kjolby M: Cost-effectiveness of intravenous thrombolysis with alteplase within a 3-hour window after acute ischemic stroke. Stroke 2007;38:85-89.

32 Cipriano LE, Steinberg ML, Gazelle GS, Gonzalez RG: Comparing and predicting the costs and outcomes of patients with major and minor stroke using the Boston Acute Stroke Imaging Scale neuroimaging classification system. AJNR Am J Neuroradiol 2009;30:703709.

33 Diringer MN, Edwards DF, Mattson DT, Akins PT, Sheedy CW, Hsu CY, et al: Predictors of acute hospital costs for treatment of ischemic stroke in an academic center. Stroke 1999;30:724-728.

34 Epstein D, Mason A, Manca A: The hospital costs of care for stroke in nine European countries. Health Econ 2008;17:S21-S31.
35 Grieve R, Hutton J, Bhalla A, Rastenytë D, Ryglewicz D, Sarti C, et al: A comparison of the costs and survival of hospital-admitted stroke patients across Europe. Stroke 2001;32:16841691.

36 Koton S, Bornstein NM, Tsabari R, Tanne D, NASIS Investigators: Derivation and validation of the prolonged length of stay score in acute stroke patients. Neurology 2010;74: 1511-1516.

37 Moon L, Moïse P, Jacobzone S, ARD-Stroke Experts Group: Stroke Care in OECD Countries: A Comparison of Treatment, Costs and Outcomes in 17 Countries. Paris, Organisation for Economic Co-operation and Development (OECD), OECD Health Working Papers 2003.

38 Dodel RC, Haacke C, Zamzow K, Pawelzik S, Spottke A, Rethfeldt M, et al: Resource utilization and costs of stroke unit care in Germany. Value Health 2004;7:144-152.

39 Luengo-Fernandez R, Gray AM, Rothwell PM: Population-based study of determinants of initial secondary care costs of acute stroke in the United Kingdom. Stroke 2006;37: 2579-2587.

40 Busse R, Schreyögg J, Smith PC: Hospital case payment systems in Europe. Health Care Manag Sci 2006;9:211-213. 